\title{
A CORRUPÇÃO NA ADMINISTRAÇÃO PÚBLICA BRASILEIRA COMO CONSEQUÊNCIA DO MODELO DE GESTÃo PATRIMONIALISTA POR ELA ADOTADO E A NECESSIDADE DE HAVER CÓDIGOS DE ÉTICA PÚBLICA
}

\author{
Caroline Fockink Ritt* \\ Eduardo Ritt ${ }^{* *}$
}

RESUMO: Este artigo científico possui como problema central: qual fórmula evitaria práticas corruptivas na administração pública, considerando-se o modelo de gestão patrimonialista adotado historicamente no Brasil? A pesquisa propõe três objetivos: apontar a dificuldade de se conceituar corrupção; evidenciar que a corrupção na administração pública é consequência do modelo patrimonialista de Estado; e demonstrar a necessidade de se adotar códigos racionais de gestão pública para se evitar práticas corruptivas. O método de abordagem é o dedutivo e o de procedimento é o histórico-crítico. A técnica da pesquisa é documentação indireta, com consulta em bibliografia de fontes primárias e secundárias.

PALAVRAS-CHAVE: Administração Pública; Códigos de ética; Corrupção; Patrimonialismo.

\section{CORRUPTION IN BRAZILIAN PUBLIC ADMINISTRATION AS A CONSEQUENCE OF PATRIMONIAL MANAGEMENT MODEL ADOPTED AND THE NEED TO HAVE PUBLIC ETHICS CODES}

\begin{abstract}
This scientific article has as its central problem: which formula would avoid corruptive practices in public administration, considering the patrimonial management model historically adopted in Brazil? The research proposes three objectives: to point out the difficulty of conceptualizing corruption; to show that corruption in public administration is a consequence of patrimonialistic state model; and to demonstrate the need to adopt rational codes of public management, in order to avoid corruptive practices. The approach method is the deductive and the procedure one is the historical-critical. The research technique is indirect documentation, with bibliographical references from both primary and secondary sources.
\end{abstract}

KEYWORDS: Public administration; Codes of ethics; Corruption; Patrimonialism.

\footnotetext{
* Caroline Fockink Ritt é doutorada em Direito. Pós doutoranda em Direito, na Pontifícia Universidade Católica PUCRS, em Porto Alegre. Mestre em Direito e Professora de Direito Penal no Curso de Direito e nas Especializações (presencial e EAD) em Direito Penal e Processual Penal da UNISC. Autora de vários artigos jurídicos e coautora do Livro Estatuto do Idoso: aspectos sociais, criminológicos e penais, editado pela Livraria do Advogado Editora, 2008, em conjunto com Eduardo Ritt. E-mail: rittcaroline@unisc.br

** Eduardo Ritt é mestre em Direito pela UNISC Professor das disciplinas de Direito Penal e Processo Penal do Curso de Direito e nas Especializações (presencial e EAD) em Direito Penal e Processual Penal da UNISC Promotor de Justiça em Santa Cruz do Sul/RS. Autor de vários artigos jurídicos e do livro O Ministério Público como Instrumento de Democracia e Garantia Constitucional, publicado pela Livraria do Advogado Editora, 2002. Coautor do Livro Estatuto do Idoso: aspectos sociais, criminológicos e penais, editado pela Livraria do Advogado Editora, 2008, em conjunto com Caroline Fockink Ritt. E-mail: eduardoritt@mprs.mp.br
} 


\section{INTRODUÇÃO}

O presente artigo científico procura buscar a resposta para a seguinte indagação, que constitui o seu problema central: qual fórmula evitaria práticas corruptivas na administração pública, levando-se em conta o modelo de gestão patrimonialista adotado historicamente na administração pública brasileira?

Para responder a referida questão, esta pesquisa é dividida em três tópicos, com os seguintes objetivos a seguir. No primeiro pretende-se demonstrar a dificuldade de se conceituar corrupção, por ser ela um fenômeno multifacetado, com características que variam dependendo do momento histórico em que ocorrem.

No segundo, tem-se a intenção de mostrar que a corrupção na administração pública pode ser considerada como consequência do modelo patrimonialista de Estado, adotado na construção da administração pública brasileira. Historicamente, na gestão pública e em seus quadros, a corrupção adveio como consequência de apadrinhamento político e nepotismo. Não há neste modelo de gestão um quadro impessoal.

Finalmente, alcançando a resposta para o problema desta pesquisa, o terceiro objetivo é apontar a necessidade de se adotar códigos racionais de gestão pública, que determinem atribuições e criem um quadro impessoal de funcionários, na administração pública brasileira. Considera-se esta como uma das fórmulas para se evitar práticas corruptivas e também punilas efetivamente, caso ocorram. O método de abordagem adotado no desenvolvimento deste estudo é o dedutivo. O método de procedimento é o histórico-crítico e, em termos de técnica da pesquisa, utilizou-se documentação indireta, com consulta em bibliografia de fontes primárias e secundárias.

\section{A DIFICULDADE EM SE CONCEITUAR A CORRUPÇÃO}

Abordar essa temática parte da complexidade de se conceituar a corrupção propriamente dita. Trazer um conceito pronto do que vem a ser a corrupção não é tarefa fácil. As dificuldades em sua conceituação vão desde a questão de se ter um agente do Estado envolvido na prática, como um funcionário ou administrador público, por exemplo, no sentido de ela estar ligada a comportamentos desviantes com relação a tais agentes, ou, de se ter ou não, necessariamente, como foco, a vantagem econômica. 


\section{A CORRUPÇÃO NA ADMINISTRAÇÃO PÚBLICA BRASILEIRA COMO CONSEQUÊNCIA DO MODELO DE GESTÃO PATRIMONIALISTA POR ELA ADOTADO E A NECESSIDADE DE HAVER CÓDIGOS DE ÉTICA PÚBLICA}

Embora o fenômeno da corrupção seja tão antigo quanto o próprio homem, ou, ainda, buscando mais exatidão, embora ela exista desde o surgimento do poder, foi, no último quarto do século XX, devido à sua generalização e aos índices registrados, que aconteceu uma preocupação maior com sua ocorrência, tanto na esfera pública, como na esfera privada. Para Pérez (2014, p. 37-38), estudioso espanhol que fundamenta este estudo, a corrupção estaria intimamente ligada ao poder, tanto ao político como ao econômico, argumentando ele, que existe uma relação muito próxima entre ambos: poder político e poder econômico. ${ }^{\dagger}$

Sila (2008, p. 575 - 576) quando se refere à questão da dificuldade de se definir a corrupção, observa que ela poderá ser abordada numa perspectiva filosófica, como também numa ótica econômica. Quando ela é abordada como questão político-cultural, questiona o citado autor, por que em determinados países aqueles comportamentos definidos como sendo de "grande corrupção" são punidos com penas duras e até com pena de morte. Ao mesmo tempo que, em outros países, vê-se estes mesmos atos de corrupção tratados com penas brandas, quando chegam a ser aplicadas. Refere-se também que outros países tratam a corrupção como uma infração da norma penal, onde ficam descartadas considerações de cunho filosófico, econômico, político e até culturais.

Gabardo (2011, p.139) observa que, ainda que a palavra corrupção seja usada comumente por todas as pessoas em rodas de conversas e discursos, geralmente quando se fala em atuação de agentes políticos, ela não possui um significado estanque, demandando um conceito multidimensional. Não é possível se verificar tão somente a corrupção sob o viés econômico ou político. Ela pode ser visualizada e estudada sob várias perspectivas, como a social, da ciência política, da teoria econômica e organizacional, da mesma forma que sob o viés da lei criminal, civil ou administrativa.

Quando se pergunta, o que vem a ser corrupção, depara-se com a dificuldade de sua definição, de saber quais condutas são consideradas práticas corruptivas. Para defini-la foram realizados estudos e análises embasados em conceituações buscadas em fontes de literatura brasileira e estrangeira.

Simão Neto (2014, p. 37), defende que o termo corrupção possui o significado de ser um ato de desvirtuamento ou de degradamento de uma regra que está socialmente ativa. O conceito

\footnotetext{
† Aunque el fenómeno es tan viejo como el hombre mismo, o, más exactamente, desde la aparición del poder, al que, como se há dicho entre nosotros, la corrupción acompaña como la sombra al cuerpo, lo cierto es que ha sido en el último cuarto del siglo XX cuando ante la generalización y cotas alcanzadas se produjo una preocupación sobre él, en ciertos sectores. Tanto la esfera pública como en la privada. Porque la corrupción está estrechamente vinculada al poder, a todo poder, al político y al económico, entre los que existe una íntima relación.
} 
de corrupção só existe por haver um conceito antônimo à situação que representa o termo honestidade. Um ser honesto é considerado um ser decente, que age ou se omite consoante o que a regra geral ensina. Embora a corrupção seja um assunto tão antigo quanto a reflexão sobre o exercício do poder público, a sua definição, conforme se ressalta, não deixa de ser problemática. Ela pode ser abordada sob perspectiva de várias formas de estudo científico, devido à multiplicidade de significados que podem ser atribuídos ao termo. Em organizações públicas, de acordo com Gómes, (2016, p.163), a prática de corrupção consistiria na utilização de suas funções e meios em benefício de seus gestores, tanto econômico, como também de outra natureza.

Procurando elementos de significação na bibliografia estrangeira, evidencia-se a dificuldade em defini-la. Conforme o conceito que venha a ser adotado sobre corrupção, será essa concepção que determinará como ela será estudada e também averiguados os índices que digam respeito a sua ocorrência. O que parece ser consenso, é que a corrupção se refere a atos em que o poder do cargo público é usado para ganhos pessoais, onde são violadas determinações que foram impostas legalmente. ${ }^{\ddagger}$ (JAIN, 2001, p. 73, http://onlinelibrary.wiley.com). Ou, conforme Etzioni (1984, p. 04), além de ser considerada um comportamento negativo, quando acontece no sistema político, seria o uso de um cargo público para se obter uma vantagem privada. Ou seja, um abuso cometido por funcionários públicos, geralmente em estreita colaboração privada. A corrupção política frequentemente acontece por interesses privados que, buscando favores públicos considerados ilícitos, encontram nos funcionários eleitos a disposição para cometer estes atos. As práticas de corrupção em um governo comumente envolvem pelo menos um parceiro público e um parceiro privado. ${ }^{\S}$

A corrupção é abordada em estudos na esfera política, quando se analisa a sua ocorrência e seus efeitos negativos, com relação às condutas políticas, fraudes eleitorais e práticas de improbidade que acontecem nas relações políticas entre agentes públicos e privados. Ademais,

\footnotetext{
$\$$ What is corruption? One of the difficulties of studying corruption lies in defining it. While it may appear to be a semantic issue, how corruption is defined actually ends up determining what gets modelled and measured. Although it is difficult to agree on a precise definition, there is consensus that corruption refers to acts in which the power of public office is used for personal gain in a manner that contravenes the rules of the game.

$\S$ Corruption, the dictionary says, is evil or wicked behavior. To corrupt is to change a sound condition to an unsound one. However, the corruption that is my subject is not regular garden-variety corruption, but the special species rampant in Washington D.C. corruption of a political system. The unsound condition I deal with is the use of public office for private advantage. This statement may seem to imply that the abuse at hand is something public officials do. Indeed they do, but usually in close collaboration with private parties. Political corruption is typically perpetrated, we shall see, by private interests seeking illicit public favors and finding quite willing elected officials. The change of the government's condition from sound to unsound often involves at least one public and one private partner.
} 


\section{A CORRUPÇÃO NA ADMINISTRAÇÃO PÚBLICA BRASILEIRA COMO CONSEQUÊNCIA DO MODELO DE GESTÃO PATRIMONIALISTA POR ELA ADOTADO E A NECESSIDADE DE HAVER CÓDIGOS DE ÉTICA PÚBLICA}

é estudada quando está ligada a aspectos econômicos, analisando-se seus efeitos negativos sobre a economia de um país e também na economia mundial. É ainda examinada com relação aos aspectos sociológicos, conforme ocorre em uma determinada sociedade, como suas conceituações mudam através dos tempos, a influência da ética pública e também da privada, em atos que são definidos como corruptivos. Além disso, é abordada no aspecto criminológico, quando a corrupção está ligada a práticas de crime organizado, lavagem de dinheiro, tanto na esfera local de um país, ou mesmo envolvendo práticas ilegais que envolvem mais de um país, e até em práticas corruptivas que financiam o terrorismo.

Cunha (2014, p. 45) entende a corrupção como o uso abusivo, por parte de um agente público ou privado, de recurso, poder ou posição inerente às suas funções, mediante a prática de qualquer ato ou omissão que implique a violação dos deveres com que foi investido. Estas práticas abusivas possuem o objetivo de conferir, ampliar ou antecipar qualquer vantagem, como também de evitar reduzir ou diferir uma desvantagem para si, para outro, para grupos de indivíduos ligados por laços de interesse comum.

Bobbio (2000, p. 291) define a corrupção como sendo a situação de um funcionário público agir de forma diferente dos padrões normativos que são estabelecidos pelo sistema, havendo um favorecimento de interesses particulares em troca de recompensa. Corrupto, nesse exemplo, seria o comportamento ilegal de quem desempenha um papel na estrutura estatal.

Mais uma vez, com o uso e pesquisa de bibliografia estrangeira, para a confecção do presente estudo, Porto (2011, http://definicion.de/corrupcion/) observa que a corrupção envolve qualquer vantagem considerada indevida, através da prática de ato ilegal ou antiético, que possa trazer benefícios para alguém ou facilitar alguma atividade. Ela seria a prática de abuso de poder, função ou meios de obter vantagem econômica. O tráfico de influência, suborno, extorsão e fraude seriam algumas das práticas corruptas que refletem esse tipo de ação, como, por exemplo, dar dinheiro a um funcionário público para ganhar uma licitação ou pagar suborno para evitar uma prisão. A corrupção poderá estar ligada a outros crimes quando, com a sua prática, ocorre a permissão para se realizar algo ilegal. Por exemplo: um policial está corrompido se ele aceitar receber dinheiro para facilitar algum roubo sem interferência da polícia. Nessa situação duas infrações estarão interligadas: a prática de corrupção e o roubo.**

\footnotetext{
${ }^{* *}$ En otro sentido, la corrupción es la práctica que consiste en hacer abuso de poder, de funciones o de medios para sacar un provecho económico o de otra índole. El tráfico de influencias, el soborno, la extorsión y el fraude son algunas de las prácticas de corrupción, que se ven reflejadas en acciones como entregar dinero a un funcionario público para ganar una licitación o pagar una dádiva o coima para evitar una clausura. A la
} 
Vários diplomas legais foram editados com o objetivo de sancionar condutas consideradas desviantes que atingem o patrimônio público. Conforme Petrelluzzi (2014, p. 19), tanto do ponto de vista legal, como no campo da ética e da moral, existem controvérsias sobre o alcance e a definição do que venha a ser corrupção. Há, entretanto, um consenso, nos diferentes tipos de análise adotados, conforme Lopes, (2011, p. 28), de que a corrupção é uma patologia social. Inclusive podem ser considerados como sendo atos de corrupção, as condutas consideradas indevidas, desvirtuantes, mas que não são necessariamente condutas que visam algum tipo de vantagem econômica.

Greco Filho (2015, p. 16) argumenta, neste sentido, que a corrupção seria também a prática de um comportamento indevido, para obter algum benefício para si ou para outrem, ainda que não tenha conteúdo econômico. Nesse conceito amplo, e que coloca mais uma vez a dificuldade de se conceituar, de uma forma definitiva e precisa o que vem a ser a corrupção, podem ser considerados atos de corrupção, por exemplo, o do empregado que assina livro de presença por outro ou o funcionário que pula a catraca controladora de entradas e saídas para assim burlar a vigilância de horário do expediente.

Este estudo preliminar que ora está sendo realizado, demonstrando a dificuldade de se definir o que é corrupção, abordando os inúmeros enfoques que podem ser dados a ela, tanto na esfera econômica, como filosófica, social e até criminológica, justamente é reforçado pelas palavras de Leal (2013, p. 82) ao destacar a ausência na tradição do pensamento político ocidental, de consenso sobre o que vem a ser a corrupção. Não há uma definição exata nesse sentido e também não se pode falar de uma Teoria Política da Corrupção. Outrossim, existem diferentes abordagens sobre o tema, a partir de marcos teóricos e filosóficos específicos.

Gabardo (2011, p.139) destaca que, embora inexistem condutas devidamente delineadas e que se enquadram como exaustivas quanto aos atos corruptos que podem acontecer, são consideradas práticas mais comuns, as que são indicadas pela Organização das Nações Unidas, quais sejam: suborno, fraude, outros pagamentos ilícitos, compra e comprometimento de valores, abuso de poder e quebra de confiança, apropriação indevida de recursos públicos e conflitos de interesses.

corrupción se encadenan otros delitos, ya que el corrupto suele incurrir en la práctica para permitir o solicitar algo ilegal. Un policía resulta corrupto si recibe dinero de un hombre para que le permita robar en una casa sin intromisión policial. En este caso, se juntan dos delitos: el acto de corrupción y el robo. 


\section{A CORRUPÇÃO NA ADMINISTRAÇÃO PÚBLICA BRASILEIRA COMO CONSEQUÊNCIA DO MODELO DE GESTÃO PATRIMONIALISTA POR ELA ADOTADO E A NECESSIDADE DE HAVER CÓDIGOS DE ÉTICA PÚBLICA}

Tendo em vista as várias formas de ser compreendido o fenômeno da corrupção, é muito difícil idealizar-se um conceito que seja suficientemente abrangente. Esta afirmação está demonstrada no presente artigo, fundamentada em bibliografia estrangeira, que evidencia a mesma dificuldade, porquanto não há uma ciência específica de seu estudo. É, na verdade, abordada em vários aspectos levando-se em conta o ambiente social e histórico em que ocorre. Além disso, ressalta-se que tal não deve ser afastada, considerando o momento histórico e ambiente social e político onde está inserida, quando o objetivo é estudá-la.

\section{RAÍZES PATRIMONIALISTAS DA CORRUPÇÃO PÚBLICA NO BRASIL}

O Brasil não seguiu um modelo racional de gestão e de administração pública devido ao fato de ter sido adotado, desde o início da história do país, um modelo que se denomina de patrimonialista. Esse modelo caracteriza-se, principalmente, pela confusão que ocorre entre a esfera pública e esfera privada. É possível demonstrar, após este entendimento, que a corrupção pública no Brasil está ligada a ele diretamente. O patrimonialismo será aqui definido, abordando também suas principais características, demonstrando que o país muito pouco adotou uma gestão racional, não respeitando a separação, que deve existir, entre o público e o privado.

Ao se procurar trazer uma definição do que vem a ser o patrimonialismo, destaca-se, conforme as lições de Max Weber (2000, p.151-152), a presença de um quadro administrativo de natureza pessoal. Nele, impera a tradição e não a adoção de estatutos legais. São beneficiadas as pessoas consideradas "associados do senhor", que devem obediência a ele e não a regras legais. O quadro administrativo e até militar, caracteriza-se por ser dominado por este senhor, que possui muito poder pessoal. A organização política do patrimonialismo não conhece nem o conceito de competência nem o de autoridade ou de magistratura, no sentido atual. A separação entre os assuntos públicos e privados, da mesma forma, entre patrimônio público e privado, e as atribuições senhoriais públicas e privadas dos funcionários, não ocorrem.

Nos ensinamentos de Paim (2015, p. 20-21), no Estado patrimonial há uma representação típica de um conjunto de tradições que são consideradas como não sendo passíveis de mudança. Tudo é baseado na tradição e em considerações pessoais. Substitui-se o domínio que deveria ser exercido por normas racionais, por outras regras, que são baseadas, além da já referida tradição, também na chamada "justiça do príncipe” e de seus funcionários. Até os privilégios que são outorgados pelo soberano são provisórios. O que ressalta Nascimento (2014, p.75-76) é que em nosso país historicamente não se respeita a separação entre o que é público e o que é 
privado. O Brasil não é um exemplo de Estado Moderno, que é legitimado por normas impessoais e racionais. Considera-se o patrimonialismo como sendo uma mazela comum, de maneira que não se promove a separação entre os meios de administração e os funcionários e governantes, fazendo com que estes tenham acesso privilegiado à estrutura e à riqueza pública para a exploração a partir de suas posições e cargos.

A tradição absolutista do período colonial trazia essa "mistura" do tesouro do Estado português com o rei e com a nobreza, que eram os principais funcionários do Estado. Relata Domingues (2012, p. 159) que a metrópole tinha uma grande dificuldade em controlar seus prepostos na América. Com as independências, Estados que tiveram estruturação formal moderna se estabeleceram, trazendo a nítida separação entre o público e o privado. Isso não implicou o desaparecimento absoluto das características patrimonialistas desses Estados, mas trouxe para eles, como consequência, uma transformação de forma decisiva.

Diferentemente de outros países da Europa que adotaram códigos racionais de gestão pública, idealizados, principalmente por Max Weber, o Brasil muito pouco adotou essa separação idealizada pelo referido pensador. Justamente, segundo Faoro (2012, p. 819-820), a legitimidade do patrimonialismo não se baseia em códigos legais de gestão, qualquer tipo de determinação legal, fundamentando-se na tradição, e essa simplesmente explica que: "assim é porque sempre foi".

É pertinente observar no Brasil o patrimonialismo adotado na gestão pública, que tem explicação na organização política, desde a época do Brasil-Colônia, também assumiu a forma de estamento. Este, conforme Weber (2000, p. 152), é caracterizado pelo domínio de uma determinada camada de pessoas com poder de mando. Tais pessoas, no quadro administrativo, formam um determinado grupo que se apropria de oportunidades econômicas. Estes apropriadores podem historicamente tanto serem originários de um quadro administrativo anterior, com caráter não estamental, como também podem não ter pertencido a esse quadro antes da apropriação.

Segundo Paim (2015, p. 27), reforçando o argumento desse estudo, o desenvolvimento histórico do patrimonialismo brasileiro, estruturado e consolidado nos primeiros séculos da história lusitana, consistiu na formação de estamento, conforme aqui explicado, com caráter burocrático. Este caráter burocrático refere-se à burocracia, não no sentido moderno, como aparelhamento racional, mas de uma organização fora do comum. A realidade, ora descrita, impede a racionalidade na gestão pública e produz como consequência um efeito estabilizador sobre a economia. Decorrente do estamento burocrático, que causa arbítrio e também 


\section{A CORRUPÇÃO NA ADMINISTRAÇÃO PÚBLICA BRASILEIRA COMO CONSEQUÊNCIA DO MODELO DE GESTÃO PATRIMONIALISTA POR ELA ADOTADO E A NECESSIDADE DE HAVER CÓDIGOS DE ÉTICA PÚBLICA}

desperdício de consumo, surge a impossibilidade de que o capitalismo industrial passe a acontecer, a fluir, pelo fato de o estamento burocrático não se compatibilizar com formas de capitalismo, no sentido de se alcançar crescimento econômico.

O patrimonialismo pessoal se transforma em patrimonialismo estatal, que adota o mercantilismo como técnica de operação da economia. Enfatiza Faoro (2012, p. 819-824) que a realidade histórica brasileira demonstrou a persistência secular da estrutura patrimonial, possuindo como principal característica um quadro administrativo com base no estamento. $\mathrm{E}$ esse quadro, esse grupo que possui poder, vai se burocratizando de forma progressiva, trazendo como consequência uma realidade de acomodação e não de uma mudança estrutural.

Salienta-se que historicamente a administração pública brasileira foi construída sobre os pilares do patrimonialismo, especificamente do patrimonialismo estamental, onde um grupo, dentro da administração pública, praticamente se apropria da máquina administrativa, formando uma "casta", que faz as suas manipulações financeiras, de concessão pública de atividade, nas atividades de controle do crédito, de consumo, e até produção privilegiada. Advém uma acomodação com base em burocracia e não há uma mudança estrutural, sendo difícil alguma alteração neste sentido. As atividades desta "casta", que na forma estamental se apropria da administração pública, acabam tendo competência sobre várias atividades, conforme já exemplificado, que vão da gestão direta até a regulamentação material da economia.

Outra característica da administração pública, que necessariamente deve ser abordada, é que no país, desde os tempos do Brasil colônia, não há a cultura de valorização da meritocracia, sendo comum sua substituição por outras formas de compensação: favores, apadrinhamentos, conchavos. A administração pública sempre foi considerada uma "longa manus" das atividades do "rei" e não organizada racionalmente e de forma impessoal. Nesta parte da história, realça Nucci (2015, p. 09-10), a meritocracia, que deveria existir na administração pública, foi substituída pelas citadas trocas de favores e conchavos palacianos, já que o ofício público era considerado como pertencente ao rei, e a própria Coroa chegou a vender cargos.

Daí já se pode observar os prejuízos que este comportamento, que deu base a práticas corruptivas, trouxe para a história brasileira. E, atualmente, verifica-se na prática o mesmo sistema. Ressalta-se que muitas nomeações políticas a cargos importantes advêm de trocas de favores, subserviência palaciana, esperteza nos relacionamentos e as sempre conhecidas “amizades" de mão dupla.

Acontece um generalizado "toma lá, dá cá". Tornou-se uma tradição brasileira o oferecimento de vantagens indevidas a servidores públicos, sendo até mesmo marginalizado 
quem não aceita suborno. Isso traz como principal consequência o cometimento de práticas corruptivas no interior da Administração Pública.

Atualmente, o patrimonialismo que existe no Brasil é nominado como sendo contemporâneo, possuindo no Estado o seu sustentáculo, pois ele se realiza conectado com outros agentes societários, os agentes do Estado que acabam se vinculando a interesses privados. Exemplifica Domingues (2012, p. 159-160), que esta forma de patrimonialismo contemporâneo, que está acontecendo no país dando ensejo a práticas de corrupção, ocorre na vinculação entre os interesses privados do indivíduo isolado que suborna o guarda de trânsito, como também com relação à grande empresa que se articula a parlamentares e a ministérios. Da mesma forma, passa pelo financiamento de campanhas eleitorais, e também nas situações onde as posições e os cargos estatais acabam sendo tomados como objeto de posse privada de seus ocupantes.

Assim, ao abordar práticas corruptivas que acontecem nesta realidade, está-se referindo ao mau uso de recursos públicos bem como à prática de imoralidades. Partindo da adoção do conceito weberiano, já estudado, que explica o que é o patrimonialismo, este passa a ser foco analítico para o problema da corrupção. Ou seja, a problemática situação de não se adotar códigos racionais de gestão, que é a principal característica da administração pública considerada moderna, não foi adotada pelo Brasil. Adotou-se historicamente quadros administrativos que são baseados na tradição e em quadros pessoais.

Conforme Nascimento, (2014, p.75-76), no modelo patrimonialista de Estado, que é inerente à construção da cena pública brasileira, a corrupção passa a ser um tipo de prática cotidiana. A tradição patrimonialista descreve a questão da corrupção como sintoma do mesmo diagnóstico: a promiscuidade que existe entre a esfera privada e a pública. Nesse sentido, o público passa a ser invadido pelos vícios da esfera privada, enquanto essa se apropria do Estado para o uso como ente "dominado" e controlado por interesses de poucos.

O que é muito importante ressaltar, e confirma o presente estudo, citando Cunha (2014, p. 46), que embasa essa argumentação, é que, justamente, nas culturas onde não há uma separação clara entre as esferas pública e privada, no que diz respeito aos titulares de cargos públicos, ou nas culturas onde estes se veem como proprietários dos poderes a eles associados, e não meros detentores de uma autoridade delegada, haverá a tendência a ter mais corrupção.

Deve ser abolida a concepção de que a coisa pública não é de ninguém. Tal concepção é consequência da ignorância popular: povo ignorante não se insurge contra o agente corrupto. Conforme Garcia (2013, p. 56-68), o agente corrupto desvia recursos públicos e os afasta das 


\section{A CORRUPÇÃO NA ADMINISTRAÇÃO PÚBLICA BRASILEIRA COMO CONSEQUÊNCIA DO MODELO DE GESTÃO PATRIMONIALISTA POR ELA ADOTADO E A NECESSIDADE DE HAVER CÓDIGOS DE ÉTICA PÚBLICA}

políticas de concreção da cidadania. O povo acaba ficando mais ignorante e dependente daquele que o lesou, sendo incapaz de romper o ciclo - quando muito, logra alterar os "personagens".

Conforme apresentado, o patrimonialismo tem origem desde a colonização de nosso país. Refletiu a organização estatal de Portugal para com suas colônias. Não se respeitou a separação entre o que é considerado público e o que é privado. Da mesma forma, os quadros pessoais da administração pública eram formados por apadrinhados do senhor, eram pessoais e não havia valorização da meritocracia. A história de nossa administração pública, em seu modelo patrimonial, não adotou, ou se houve, pouco respeitou, as determinações legais que dessem uma roupagem de gestão pública em moldes racionais, com disciplina e organização impessoais, nos moldes idealizados por Max Weber.

Daí a necessidade de se adotar códigos de ética pública, para justamente evitar esta confusão entre o que é público e privado, reflexo da cultura patrimonialista, que foi adotada pela administração pública, historicamente. Este ponto será abordado a seguir.

\section{A NeCESSidade de Adoção de Códigos de ÉtiCa pública para EVITAR PRÁTICAS CORRUPTIVAS NA ADMINISTRAÇÃo PÚBLICA}

Uma das mais importantes características, na criação do Estado Moderno, é a separação entre público e privado. Essa concepção surgiu na Europa Ocidental com o pensamento liberal e teve em Max Weber o seu maior teórico. Tal modelo está presente na totalidade dos países europeus e nas Américas, e, da mesma forma, em outras partes do mundo. Conforme ressalta Leal (2013, p. 48), um dos elementos essenciais na constituição do Estado Moderno e Contemporâneo, tomando por base a perspectiva de Max Weber, foi justamente a formação de uma administração burocrática idealizada em moldes racionais.

Weber (2000, p. 142) idealizou a forma de um quadro administrativo que seja burocrático. Este quadro deverá, principalmente, aderir à legalidade, baseado em ideias que devem estar entrelaçadas entre si, quais sejam: a de que todo direito deve ser estatuído de modo racional, tanto referente a fins como a valores, ou até a ambas as coisas, através de um pacto ou de imposição. Para ele, o direito é um conjunto de regras abstratas, que normalmente são estatuídas com determinadas intenções. Administração é justamente este cuidado, que é racional, de interesses que estão previstos pelas ordens da associação, dentro dos limites das normas jurídicas e conforme os princípios que estão indicados de forma geral. 
Neste modelo racional de gestão, quem ordena o faz observando as disposições impessoais que orientam as suas diretrizes, e quem obedece, o faz como membro da associação e somente atende ao direito. Então, na administração a ideia aplicada é a de que os membros da associação, quando obedecem não estão se sujeitando a disposições pessoais de nenhum senhor, como acontece no patrimonialismo, por exemplo. Mas, quando obedecem, neste modelo racional, idealizado por Weber, estão cumprindo aquelas ordens que são legais e impessoais. Estão obrigados somente à obediência dentro da uma competência que é objetiva e que é racionalmente limitada. São ordens legais e abstratas.

Com estas disposições racionais de gestão pública, os envolvidos na administração pública devem cumprir ao que está determinado legalmente, pois é ela quem dá toda a legitimidade na administração. Leal (2013, p. 48-49) observa que, neste modelo, o poder político ganhou um caráter racional, uma vez que a crença na legalidade das ordens que são emanadas e na legalidade da competência dos indivíduos escolhidos para exercê-lo, tem uma qualidade diferente do que ocorre na crença da tradição ou do carisma. Então, é a própria racionalidade, inerente à forma jurídica que proporciona legitimidade àquele poder político, que é exercido de forma legal.

Weber (2000, p. 143) idealizou também o que chamou de categorias fundamentais da dominação racional. Para ele, quando as funções são exercidas, ficam dentro de um exercício contínuo, que está vinculado a determinadas regras, e dentro de uma determinada competência. O exercício organizado dessa função é chamado de autoridade institucional. Nela estão juntos o princípio da hierarquia oficial, que é a organização de instâncias fixas de controle e supervisão para cada autoridade institucional, como também o direito de apelação ou reclamação dos subordinados aos superiores. As regras as quais se procede são as técnicas e as normas. E, para aplicação dessas ideias, com o objetivo de atingir racionalidade plena, é necessário, em ambos os casos, uma qualificação profissional. Assim, somente os que comprovam uma especialização profissional podem ser aceitos como funcionários.

Nesta racionalidade administrativa idealizada pelo autor referido, aplica-se também o Princípio da Separação Absoluta entre o quadro administrativo e os meios de administração e de produção. Isso significa que os funcionários, empregados e trabalhadores do quadro administrativo não estão de posse dos meios materiais de administração e de produção. Eles os recebem em espécie ou em dinheiro e possuem responsabilidade contábil. Nesta proposta vê-se a separação entre o que é público e o que é considerado privado, aplicando-se o princípio da separação absoluta entre o patrimônio (ou capital) da instituição (empresa) e o patrimônio 


\section{A CORRUPÇÃO NA ADMINISTRAÇÃO PÚBLICA BRASILEIRA COMO CONSEQUÊNCIA DO MODELO DE GESTÃO PATRIMONIALISTA POR ELA ADOTADO E A NECESSIDADE DE HAVER CÓDIGOS DE ÉTICA PÚBLICA}

privado (da gestão patrimonial), como também entre o local das atividades profissionais (escritório) e o domicílio dos funcionários. E, para atingir a racionalidade plena, deve ser aplicado também o princípio da documentação dos processos administrativos, mesmo nas situações em que a prática seja a discussão oral. Equivale a dizer que, pelo menos, as considerações preliminares e requisitos, como também as decisões, disposições e ordenações finais de todas as espécies, devem estar estabelecidos por escrito.

Finalmente, para Weber (2000, p. 144), o tipo mais puro de dominação legal é aquele que se exerce por meio de um quadro administrativo burocrático. O conjunto do quadro administrativo deverá ser composto de funcionários individuais que são pessoalmente livres, e que obedecem somente às obrigações objetivas de seu cargo. Esse quadro administrativo será nomeado e não eleito. Obedecerá uma hierarquia rigorosa de cargos que possuem competências funcionais fixas, de acordo com um contrato, seguindo a livre seleção, com base na qualificação profissional. No caso mais racional, essa qualificação é verificada mediante prova e certificada por diploma. Serão remunerados por salários fixos e em dinheiro. Na maioria dos casos, com direito à aposentadoria. Exercem sua profissão como sendo a única ou principal atividade. Têm perspectiva de ocorrer progressão na carreira, por tempo de serviço ou eficiência, ou por ambas as coisas. Trabalham em separação absoluta dos meios administrativos e sem apropriação do cargo. Estão sujeitos a um sistema que é rigoroso e homogêneo de disciplina e de controle de serviço.

Partindo do acima exposto, que fundamenta a gestão pública, nos principais países da Europa, com base na legalidade, nos moldes racionais e burocráticos de hoje, observa Domingues (2012, p. 158) que, nesta ideia, o patrimônio estatal, que agora é público, está separado de seus governantes e funcionários. Afirmação que se contrapõe a uma visão patrimonialista do Estado, em que as posições e cargos devem ser naturalmente explorados por governos e por funcionários, sem distinção entre os recursos privados e os do Estado. Tais recursos também advinham da exploração daquelas posições e cargos em que o trabalho não exigia muito esforço, embora lhes permitisse extrair várias benesses pessoais.

Observa-se que o Brasil não respeita, ou pouco adotou, essa forma racional de gestão idealizada por Weber. Historicamente, como relatado, a gestão pública brasileira foi baseada no patrimonialismo, que tem como fundamento não a racionalidade de gestão, mas a tradição. Vivendo-se numa realidade onde ocorre "confusão" entre o público e o privado, é justamente essa realidade que potencializa a ocorrência de práticas corruptivas. 
Ressalta Leal (2013, p. 48) que pelo modelo racional de Max Weber, as ordens estatais são manifestações do poder político, por isso possuem caráter racional. O Poder deve ser moldado por uma forma de racionalidade, que é a lei. A Legalidade é quem garante a qualidade formal da administração do Poder e da Administração Pública, com base em princípios, visando com isso à segurança social.

Daí surge a importância da ética pública, justamente de se seguir os regulamentos racionais, impostos para a Administração Pública para serem observados pelos seus servidores e com relação às pessoas que se relacionam com ela, no contexto administrativo. Se bem estabelecidos com o cumprimento de suas determinações, com punição rigorosa de seus transgressores, serão uma eficiente forma de evitar e punir práticas corruptivas.

Ética pública se constituiria como sendo a ordem considerada justa e estável, ou seja, a base da organização social. Dentre os destinatários da ética pública estão as autoridades, profissionais do direito, os legisladores, os juízes e os funcionários e, da mesma forma, cada pessoa, considerada como cidadã.

Usando bibliografia estrangeira, nas palavras de Cortina (1998, p. 98), a ética tem um valor de uso, e não somente a pessoal, mas também a ética das organizações e das instituições da vida pública. Para a autora, é certo que as instituições e as organizações públicas que funcionam eticamente obtêm a legitimidade e devem ser credoras em realizar bem a sua tarefa, que é a obrigação ligada a qualquer organização de cumprir a sua missão, principalmente diante da cidadania, cada vez mais consciente das funções das instituições públicas. ${ }^{\dagger \dagger}$

Para combater o mal da corrupção e alcançar a boa administração pública, necessário se faz estabelecer, em regulamentos, disposições de comportamentos que sejam considerados éticos que devem ser adotados na esfera pública e também na esfera privada.

A ética pública, mais uma vez nas palavras de Cortina (1998, p. 98-101), é considerada fundamental, um produto de primeira necessidade na vida pública. ${ }^{+}$Sem ela as grandes instituições do mundo moderno e "pós-moderno", ou seja, o Estado, a economia e os negócios, as atividades profissionais e de trabalho, terceiro setor ou setor social, simplesmente não

\footnotetext{
"Sin embargo, no es menos cierto que también la ética tiene un valor de uso, y no sólo la ética personal, sino también la ética de las organizaciones e instituciones de la vida pública, que es la que ahora nos importa. También es cierto que las instituciones y organizaciones públicas sólo si funcionan éticamente ganan la legitimidad a que deben hacerse acreedoras ante una ciudadanía cada vez más consciente de serlo y también la viabilidad, el permanecer realizando su tarea, que es la obligación a la que está ligada cualquier organización.

$\$[. .$.$] la ética es un producto de primera necesidad en la vida pública, porque en ella las medidas jurídicas, con$ ser necesarias, resultan insuficientes.
} 


\section{A CORRUPÇÃO NA ADMINISTRAÇÃO PÚBLICA BRASILEIRA COMO CONSEQUÊNCIA DO MODELO DE GESTÃO PATRIMONIALISTA POR ELA ADOTADO E A NECESSIDADE DE HAVER CÓDIGOS DE ÉTICA PÚBLICA}

funcionam. É de conhecimento comum que as relações sociais são quebradas, embora aparentemente continuem a trabalhar, quando lhes falta o suporte de valores, como a credibilidade e a confiança. ${ }^{\S \S}$

Conforme Mileski (2015, p. 145-147), foi a partir do final dos anos 90 do século XX, que esta questão passou a orientar a necessidade de implantação de Códigos de Ética em todos os níveis governamentais ou Administrativos. Para o referido autor, deverá haver uma ética negativa, que contribua para erradicar comportamentos abusivos, fraudulentos, prevaricadores, que já foram tipificados como delitos e como infrações administrativas. Deve, também, ser fomentada uma ética positiva, no sentido de ser reavivado o serviço público e seus valores, como também o compromisso com as tarefas e funções do poder público.

Vários países passaram a ter a inciativa de elaborarem seus códigos de ética pública. A título de exemplificação, serão citados alguns. A primeira referência é relativa aos Princípios de Conduta Ética nos Estados Unidos da América, pois se trata de um país com larga experiência em matéria de normas éticas na Administração Pública. Pelo Decreto nº 12.731, de 1989, foram estabelecidos os Princípios de Conduta Ética, na seguinte forma: Legalidade, Conflito de interesses, honradez, integridade, honestidade, responsabilidade, impessoalidade, imparcialidade, austeridade, diligência, boa-fé, objetividade e imparcialidade, exemplaridade.

Em Portugal (Diário da República 1993, p. 1272-1273, https://www.isa.ulisboa.pt) na Carta do Serviço Público Português (1993), são enumerados, como valores fundamentais dos funcionários públicos: o exercício de suas funções em exclusivo interesse do serviço ou do interesse público; a neutralidade em todas as situações em que se compreende a objetividade e a imparcialidade; a responsabilidade; a competência com relação à eficiência e à integridade para que não aceitem doações ou outros tipos de presentes.

No Reino Unido foi publicado, em maio de 1995, o Relatório Nolan (Nolan, 1995. http://www.enap.gov. br), documento considerado primordial para a discussão dos padrões de comportamento ético dos servidores públicos, dos políticos, tanto dos parlamentares como dos altos dirigentes de governo. Boa parte dessas recomendações foram adotadas e implementadas no Reino Unido e, atualmente, são analisadas e estudadas por universidades em todo o mundo. O documento aborda temas como responsabilidade ética, imparcialidade e corrupção dos

\footnotetext{
$\S$ La ética es en la vida pública un producto de primera necesidad, en principio, porque sin ella no funcionan las grandes instituciones del mundo moderno y "postmoderno", es decir, el Estado, la economía y la empresa, las actividades profesionales y el "Tercer Sector" o "Sector Social”. Es público y notorio que las relaciones sociales se quiebran, aunque en apariencia sigan funcionando, cuando faltan en ellas, prestándoles un soporte, los valores de credibilidad y confianza.
}

Rev. de Direito Administrativo e Gestão Pública | e-ISSN: 2526-0073 | Porto Alegre | v. 4 | n. 2 | p. 1 - 20 | Jul/Dez. 2018 
funcionários públicos. Os sete princípios da vida pública, recomendados pelo referido Relatório são: interesse público, integridade, objetividade, "accountability" (no sentido de prestação de contas), transparência, honestidade e liderança. Sobre cada um deles são inúmeras as referências e situações que o texto apresenta, tanto em relação a políticos como a servidores públicos.

Já a Organização para a Cooperação e o Desenvolvimento Econômico (OCDE), por proposta do Comitê da gestão pública, em 1996, realizou uma série de recomendações para que os países que o integram, adotem medidas destinadas a controlar o bom funcionamento das instituições, buscando fomentar um comportamento de acordo com a ética do serviço público.

Lembra Leal (2013, p. 65) que o Brasil possui vários documentos que tratam do tema da Ética Pública, especialmente o Código de Ética Profissional do Servidor Público Civil, do Poder Executivo Federal e o Código de Conduta de Alta Administração Federal. E as normas básicas que visam à proteção dos direitos dos administradores, objetivando o melhor cumprimento dos fins públicos, estão previstas na Lei 9.784 de 29/01 de 1999, que regula o processo administrativo no âmbito da Administração Pública Federal.

O Brasil tem o sistema de declaração de bens dos servidores públicos em geral, a Lei $\mathrm{n}^{\circ}$ 3.164, de 01/07/ 1957, que é considerada importante ferramenta para a proteção da ética pública. Ela instituiu o registro público obrigatório de valores e bens pertencentes ao patrimônio privado daqueles que exercem cargos públicos na União, entidades autárquicas, eletivas ou não. Também a Lei 8.730, de 10/11/93, estabelece obrigatoriedade de todos os agentes políticos e membros da magistratura e do Ministério Público da União - que apresentem declaração de bens, indicando fontes de renda, no momento da posse e no final de cada exercício financeiro.

A ideia de atender sempre aos interesses gerais é que deve reger as ações de qualquer um que realiza uma função pública, tanto a autoridade, como o funcionário público ou o político. Eles servem ao Estado e outras entidades públicas e não a algum tipo de parcialidade política ou econômica. E, de acordo com Cortina (1998, p. 99), o descrédito que acontece nas instituições, devido à ocorrência de práticas de corrupção, não somente é imoral ou ilegal, mas desmoraliza, e, o que a autora chama de "tirar o ânimo", a médio e a longo prazos, da sociedade considerada em seu conjunto. Em uma sociedade desanimada e apática, não é possível construir-se nada sólido.***

${ }^{* * * *}$ Cierto que si el engañado es débil, en indignación o en desidia queda su desacuerdo, porque el derecho es
eficaz sólo en manos de los poderosos. Pero no es menos cierto que este paulatino descrédito de las instituciones Rev. de Direito Administrativo e Gestão Pública | e-ISSN: 2526-0073 | Porto Alegre | v. 4 | n. 2 | p. 1 - 20 | Jul/Dez. 2018 


\section{A CORRUPÇÃO NA ADMINISTRAÇÃO PÚBLICA BRASILEIRA COMO CONSEQUÊNCIA DO MODELO DE GESTÃO PATRIMONIALISTA POR ELA ADOTADO E A NECESSIDADE DE HAVER CÓDIGOS DE ÉTICA PÚBLICA}

Nas palavras de Leal (2013, p. 69) a corrupção pode atingir qualquer situação, fase ou variável dos processos de trabalho, do processo de decisões e até de executivos das instituições. A corrupção pode estar presente desde a solicitação para realizar os processos, como na concepção e no planejamento dos mesmos, bem como em suas fases preparatórias, na execução, e inclusive, da mesma forma quando ocorre a apresentação dos resultados.

Com isso, demonstra-se o quanto é necessário se combater a corrupção, através de códigos de ética pública, que estabeleçam quais os comportamentos que deverão ser adotados para aqueles que trabalham na administração pública e também para os que, em algum momento, se relacionam com ela. Ademais é fundamental que aqueles que praticam comportamentos desviantes tenham exemplares punições, estabelecidas nos referidos códigos, pois a impunidade retroalimenta os comportamentos corruptivos e traz ainda mais descrédito e desconfiança às instituições.

\section{CONCLUSÃO}

O presente artigo científico procurou responder o problema: qual fórmula evitaria práticas corruptivas na administração pública, levando-se em conta o modelo de gestão patrimonialista adotado historicamente no Brasil?

Para se chegar a resposta ao problema proposto estabeleceu-se alcançar três objetivos: o primeiro buscou demonstrar a dificuldade de se conceituar a corrupção, por ser ela um fenômeno multifacetado, que possui características que variam dependendo do momento histórico em que ocorrem. Nesse estudo adotou-se como definição as práticas consideradas mais comuns, indicadas pela Organização das Nações Unidas, quais sejam: suborno, fraude, outros pagamentos ilícitos, compra e comprometimento de valores, abuso de poder e quebra de confiança, apropriação indevida de recursos públicos e conflitos de interesses.

Num segundo momento evidenciou-se que a corrupção na administração pública é consequência do modelo patrimonialista de Estado, adotado historicamente na gestão pública brasileira. Neste ponto, mostrou-se que a corrupção adveio como consequência de apadrinhamento político e nepotismo, pois nesse modelo de gestão não há um quadro impessoal. $\mathrm{O}$ modelo mencionado caracteriza-se, principalmente, pela confusão que acontece

no sólo es inmoral, no sólo es ilegal, sino que desmoraliza, roba el ánimo al medio y largo plazo a la sociedad en su conjunto, y en una sociedad desanimada no puede emprenderse nada sólido 
entre a esfera pública e esfera privada. E, como consequência, ocorrem inúmeras práticas corruptivas.

Finalizando o presente artigo, ressalta-se a necessidade de se adotar códigos racionais de ética pública, idealizados pelo pensador Max Weber. A maioria, senão todos os países ocidentais, adotam este modelo racional de administração pública.

Tais códigos evitariam práticas corruptivas, pois estabelecem racionalmente como a gestão pública deverá estar organizada e, definem o comportamento adequado que os integrantes da administração pública devem ter, principalmente quando se relacionam com agentes externos, de modo especial, da esfera privada. Os referidos códigos de ética pública também determinam que deverá acontecer a punição efetiva para aqueles que cometem práticas corruptivas na administração pública.

Esta é uma das formas eficientes, na opinião desta pesquisadora, para combater a corrupção na gestão pública, que é, conforme demonstrado no presente estudo, consequência da administração patrimonialista adotada historicamente no Brasil.

\section{REFERÊNCIAS}

BOBBIO, N.; MATTEUCI, N.; PASQUINO, G. Dicionário de política. 5. ed. Brasília: Editora Universidade de Brasília: São Paulo: Imprensa Oficial do Estado de São Paulo, 2000.

CORTINA, Adela. Hasta um pueblo de demônios: ética pública y sociedade. Madrid, España: Santillana/Taurus, 1998.

CUNHA, Ary Ferreira da. Causas e consequências da corrupção: uma breve introdução jurídico-económica. In: CUNHA, Ary Ferreira (Coord.). IV Congresso de Direito Fiscal. Porto: Quid Juris Sociedade, 2014.

DOMINGUES, José Maurício. Patrimonialismo e Neopatrimonialismo. In: AVRITZER,. et al. (Org.). Corrupção: ensaios e críticas. Belo Horizonte: Editora UFMG, 2012.

ETZIONI, Amitai. Capital corruption: the new attack on American democracy. San Diego: Harcourt Brace Jovanovich, 1984.

FAORO, Raymundo. Os donos do poder: formação do patronato político brasileiro. 5. ed. São Paulo: Globo, 2012.

GABARDO, E.; REIS, L. E. O gerencialismo entre eficiência e corrupção: breves reflexões sobre os percalços do desenvolvimento. In: SILVEIRA, R. D. da; CASTRO, R. A. P. de. (Org.). Estudos dirigidos de gestão pública na América Latina. Belo Horizonte: Fórum, 2011. 


\section{A CORRUPÇÃO NA ADMINISTRAÇÃO PÚBLICA BRASILEIRA COMO CONSEQUÊNCIA \\ DO MODELO DE GESTÃO PATRIMONIALISTA POR ELA ADOTADO E A NECESSIDADE DE HAVER CÓDIGOS DE ÉTICA PÚBLICA}

GARCIA, E.; ALVES, R. P. Improbidade administrativa. 7. ed., rev., ampl. e atual. São Paulo: Saraiva, 2013.

GÓMES, Santiago Roura. Alguns aspectos-chave do combate à corrupção na Administração Pública. In: MENDES, G.F.; BRANCO, P.G.G. V Seminário Internacional de Direito Administrativo e Administração Púbica - Tendências da Administração Pública- Escola de Administração de Brasília - IDP. Série IDP Eventos. Brasília, 2016.

GRECO FILHO, V.; RASSI, J. D. O combate à corrupção e comentários à Lei de Responsabilidade das Pessoas Jurídicas (Lei $n$. 12.846, de $1^{\circ}$ de agosto de 2013): atualizado de acordo com o Decreto n. 8.420, de 18 de março de 2015. São Paulo: Saraiva, 2015.

JAIN, Arvind K. Corruption: a review. Journal of Economic Surveys. Volume 15, Issue 1, February 2001. Disponível em: <http://onlinelibrary.wiley.com/doi/10. 1111/ 14676419.00133/epdf>. Acesso em: 15 ago. 2016.

LEAL, Rogério Gesta. Patologias corruptivas nas relações entre Estado, administração pública e sociedade: causas, consequências e tratamentos. Santa Cruz do Sul: EDUNISC, 2013.

LOPES, José Mouraz. O espectro da corrupção. Coimbra, Portugal: Almedina, 2011.

MILESKI, Helio Saul. O Estado contemporâneo e a corrupção. Belo Horizonte: Fórum, 2015.

NASCIMENTO, Melillo Dinis do. O controle da corrupção no Brasil e a Lei nº 12.846/2013 Lei Anticorrupção. In: . Lei Anticorrupção empresarial: aspectos críticos à Lei $\mathrm{n}^{\circ}$ 12.846/2013. Belo Horizonte: Fórum, 2014.

NOLAN, Lord. Normas de Conduta para a vida pública. Cadernos ENAP, Fundação Escola Nacional de Administração Pública. Normas de conduta para a vida pública. Disponível em: < http://www.enap.gov.br/ documents/ 52930/707 328 /cad12.pdf/ a9405ff4-494d-402c-b8641012813771c2>. Acesso em: 03 nov. 2017.

NUCCI, Guilherme de Souza. Corrupção e anticorrupção. Rio de Janeiro: Forense, 2015.

PAIM, Antonio (Org.). O patrimonialismo brasileiro em foco. Campinas: VIDE, 2015.

PÉREZ, Jesús Gonzáles. Corrupción, ética y moral em las administraciones públicas. 2. ed. España: Thomson Reuters, 2014.

PETRELlUZZI, M. V.; JUNIOR RIZEK, R. N. Lei Anticorrupção: origens, comentários e análise da legislação correlata. São Paulo: Saraiva, 2014.

PORTO, J. P.; MERINO, M. 2011. Definición de corrupción. Disponível em: $<$ http://definicion.de/corrupcion>. Acesso em: 04 jun. 2018.

PORTUGAL. Diário da República - I - Série B. No 64, 17-3-1993. Páginas: 1272- 1273. Disponível em: <.https://www.isa.ulisboa.pt/files/daf/nrh/pub/docs /enquadra mentolegal/18_93.pdf>. Acesso em: 30 abr. 2017. 
SILA, Jorge da. Criminologia Crítica: Segurança Pública e Polícia. Rio de Janeiro: Forense, 2008.

SIMÃO NETO, Calil. Improbidade administrativa: teoria e prática: de acordo com a Lei ${ }^{\circ}$ 12.846 de 01 de agosto de 2013, com a lei complementar nº 135 de junho de 2010: Ficha Limpa. 2. ed. Leme: J. H. Mizuno, 2014.

WEBER, Max. Economia e sociedade: fundamentos da sociologia compreensiva. 4. ed. Brasília: Editora Universidade de Brasília, 2009 (reimpressão). 